\title{
Chirp investigation in EMLs towards frequency shift keying modulation
}

Iglesias Olmedo, Miguel; Vegas Olmos, Juan José; Westergren, Urban; Popov, Sergei; Tafur Monroy, Idelfonso

\section{Published in:}

Proceedings of Asia Communications and Photonics Conference 2014

Publication date:

2014

Link back to DTU Orbit

Citation (APA):

Iglesias Olmedo, M., Vegas Olmos, J. J., Westergren, U., Popov, S., \& Tafur Monroy, I. (2014). Chirp investigation in EML's towards frequency shift keying modulation. In Proceedings of Asia Communications and Photonics Conference 2014 Optical Society of America.

\section{General rights}

Copyright and moral rights for the publications made accessible in the public portal are retained by the authors and/or other copyright owners and it is a condition of accessing publications that users recognise and abide by the legal requirements associated with these rights.

- Users may download and print one copy of any publication from the public portal for the purpose of private study or research.

- You may not further distribute the material or use it for any profit-making activity or commercial gain

- You may freely distribute the URL identifying the publication in the public portal

If you believe that this document breaches copyright please contact us providing details, and we will remove access to the work immediately and investigate your claim 


\title{
Chirp investigation in EMLs towards frequency shift keying modulation
}

\author{
Miguel Iglesias Olmedo ${ }^{(1,2)}$, J.J. Vegas Olmos ${ }^{(1)}$, Urban Westergren ${ }^{(2)}$, Sergei Popov ${ }^{(2)}$, \\ Idelfonso Tafur Monroy ${ }^{(1)}$, \\ (2) DTU Fotonik, Technical University of Denmark (DTU), 2800 Kgs. Lyngby, Denmark. \\ (1) Optics division, Royal Institute of Technology (KTH), Electrum 229, Kista, SE-164 40, Sweden. \\ molm@fotonik.dtu.dk
}

\begin{abstract}
This paper presents a chirp modeling and experimental results that support our vision of enabling frequency shift keying (FSK) exploiting the chirp effect in externally modulated lasers (EMLs).
\end{abstract}

OCIS codes: $060.0060,060.2630$.

\section{Introduction}

Optical networks have experienced a dramatic technological growth, moving to higher bandwidth capacities to satisfy the traffic growth [1]. Hence, there has been a lot of research on high capacity modulators, especially externally modulated lasers (EMLs), which are the key block in charge of the electro-optical conversion process. Electro-absorption modulators (EAMs) currently offer the largest bandwidth, reaching $100 \mathrm{GHz}$ [2], followed by $40 \mathrm{GHz}$ achieved by mach-zehnder modulators (MZMs) employing electro-optic effects [3]. In addition, EAMs offer several advantages such as yielding integration with distributed feedback (DFB) lasers, which strongly minimizes insertion losses, and require low driving voltages. The chirp effect in EAMs is however considerably higher than in intensity modulators based on mach-zehnder interferometer (MZI) structures [4]. This becomes a problem when dispersion interacts with the chirp and creates inter symbol interference (ISI), raising the bit error rate (BER) of the transmission link, and is considered the most important shortcoming of EAMs. In this paper, based on a chirp model developed in-house, we present experimental measurements of the chirp of a $40 \mathrm{GBit} / \mathrm{s}$ DFB-EAM and argument the possibility of developing frequency shift keying (FSK) modulation.

\section{Modeling the chirp on an EAM}

The chirp is the change of the frequency over time. This change in frequency is produced in the rise and fall edges of a traveling pulse in the EAM, and find its roots in the Kramers-Kronig relations which conditions are fulfilled by the refractive index of the medium (Eq. 1) where the complex refractive index $n=n^{\prime}+j n^{\prime \prime}$. This means that a change on
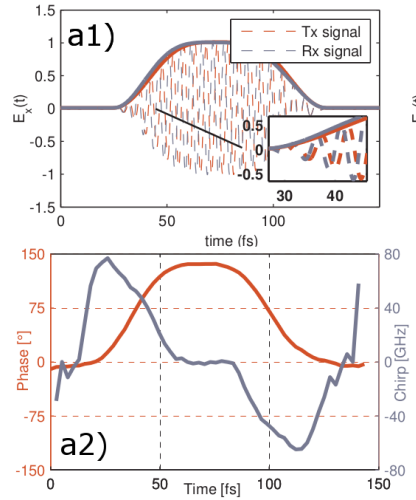
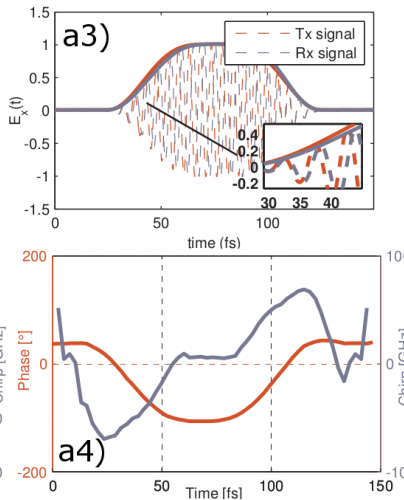
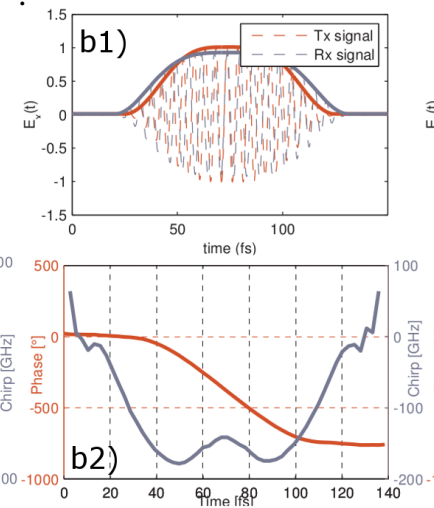
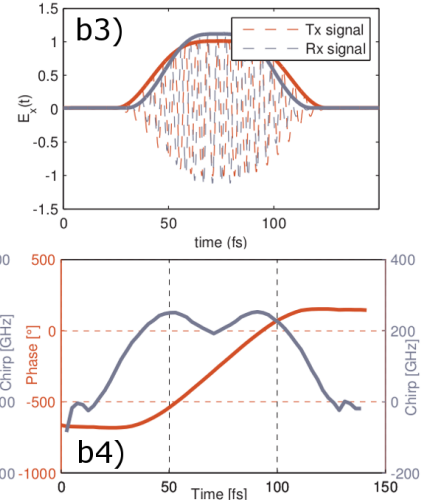

Fig. 1. Comparison between source and received signal after propagation of: (a) $1 \mu \mathrm{m}$ and (b) $48 \mu \mathrm{m}$. 
the amplitude of the electric field will inherently induce a change in the phase (Eq. 2) [4] where $S$ is the instantaneous power and $\alpha$ is the chirp factor.

$$
\begin{aligned}
& \frac{\partial n^{\prime}}{\partial t}=\alpha \frac{\partial n^{\prime \prime}}{\partial t} \\
& \frac{\partial \phi}{\partial t}=\frac{\alpha}{2 S} \frac{\partial S}{\partial t}
\end{aligned}
$$

In order to model the chirp and simulate its effect upon propagation, we rely on the Finite Difference Time Domain (FDTD) method, which consists on solving the Maxwell equations in discretized grids of time and space. This simulation was performed with a $60 \mu \mathrm{m}$ space grid of 6000 nodes and a $1 \mathrm{ps}$ time grid of 10724 nodes.

Fig. 1 shows the simulation results for a positive ( $1^{\text {st }}$ and $2^{\text {nd }}$ column) and negative $\left(2^{\text {nd }}\right.$ column$)$ chirped pulse with a spectral width of $10 \mathrm{THz}$ propagating at the $1.55 \mu \mathrm{m}$ wavelength over 1 and $48 \mu \mathrm{m}$ (a \& b insets, respectively).

It can be observed a chirping of $\pm 50 \mathrm{GHz}$ taking place at the edges of the pulse before propagation, which leads to a broadening of the pulse in case of positive chirp, or a contraction in case of negative chirp. The phase analysis of the received chirped pulse in Fig. 1 with respect to the ideal leads to insets a2, a4, b2 and b4, where the chirp as the deviation in frequency with respect $c / \lambda_{0}$ is also shown. It is worth pointing out that, upon propagation, both chirp and phase information are integrated, and since the chirp is the derivative of the phase, the information of the phase encoded in the receiver is transferred into the chirp after propagation. This could pave the way for frequency shift modulation formats using electro-absorption modulators, which is a functionality being studied in the field of all-optical signal processing [5].

\section{Experimental measurements of the chirp}

Fig. 2 shows the setup of the experiment. A pseudo-random pattern generator (PPG) generates a $12.5 \mathrm{~Gb} / \mathrm{s} \mathrm{NRZ}$ signal that is applied to the EAM. The EAM is temperature controlled using a thermo-electrical cooler (TEC), and an adjustable power supply provides the bias voltage. The received back-to-back (B2B) signal is analyzed with an optical complex spectrum analyzer (OCSA). This device was able to coherently detect the incoming light beam and, with the real and complex part of the spectrum, perform the inverse fast Fourier transform (IFFT) to obtain time domain measurements including both amplitude and phase; chirp and $\alpha$ parameters were calculated then analytically. Fig. 3a shows the measured relation between the optical output power and the chirp parameter, for bias voltages ranging from 1.5 to $3 \mathrm{~V}$. As it can be observed, the extinction ratio of the modulator is around $10 \mathrm{~dB}$, while $\alpha$ ranges from -0.5

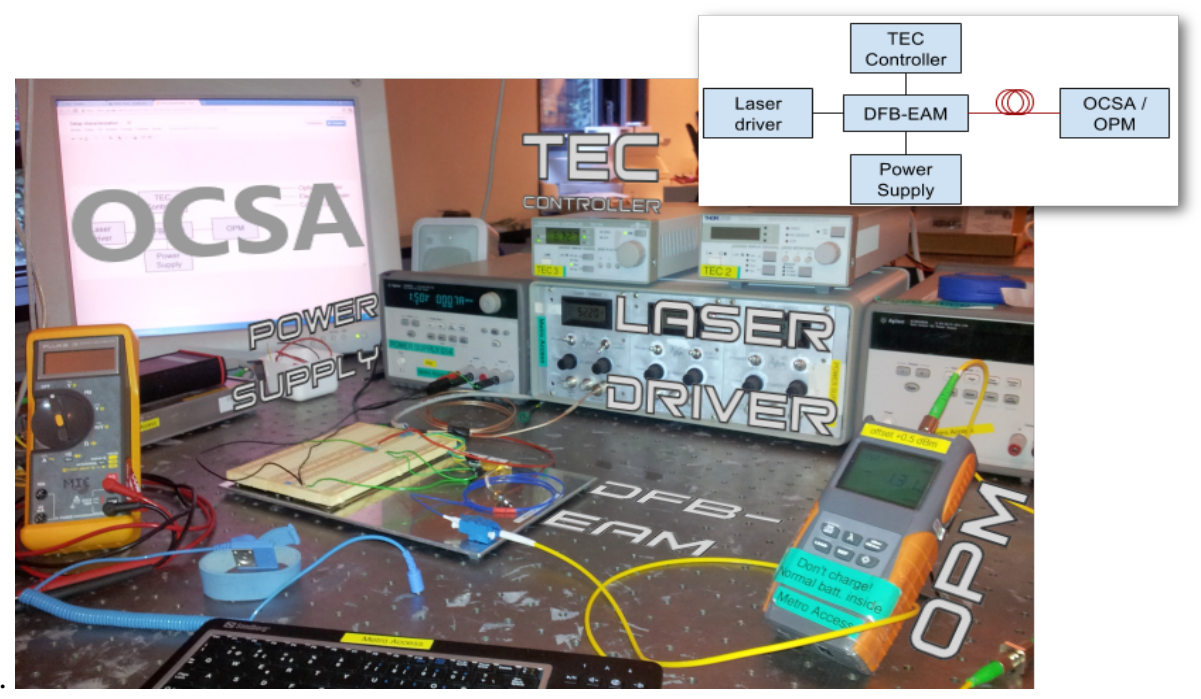

Fig. 2. Experimental Setup. OCSA: Optical complex spectrum analyzer. OPM: Optical power meter. TEC: Thermo-electric cooler. 

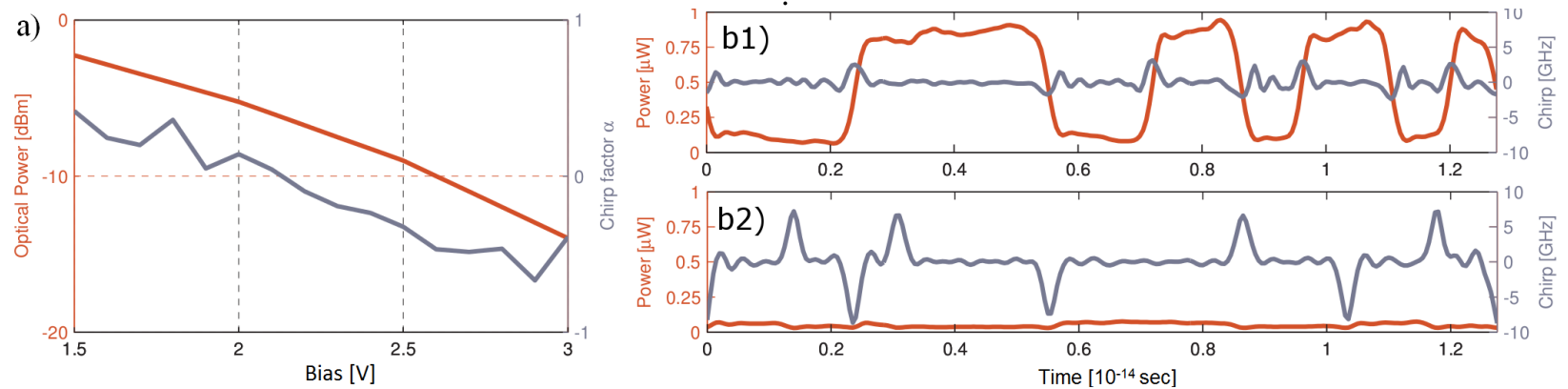

Fig. 3. a) Measured output power and $\alpha$ parameter as a function of the reverse bias voltage applied to the EAM. b) Amplitude, phase and chirp information of the time-domain recovered signal for (1) bias $=1.5 \mathrm{~V} \& \alpha=0.417$ and (2) bias $=3 \mathrm{~V} \& \alpha=-0.39$.

to 0.5. Both the optical power and the chirp factor exhibit a linear response with respect the bias voltage. One of the consequences of operating at negative chirp regimes is the reduction in the output extinction ratio, since the bias voltage required must be above $2.2 \mathrm{~V}$. However, when combined with positive dispersion media, it has been shown to effectively counteract dispersion. Therefore the possibility of transferring the phase information into frequency via chirp profiles as an attractive solution. Fig. $3 b$ shows time-domain measurements of the signal obtained with the OCSA. It shows the power as well as the chirp measurements for 1) $\alpha=0.417$ and 2) $\alpha=-0.39$. In the first case, we observe a good extinction ratio and a positive chirp of $\pm 4 \mathrm{GHz}$ while for the second case, a $\pm 8 \mathrm{GHz}$ negative chirp is observed as well as very weak signal. The results are in agreement with the simulation results. Quantified difference in frequency offset can be explained by the fact that the experimental bitrate was $12.5 \mathrm{~Gb} / \mathrm{s}$, while the simulated pulse had a spectral with of $10 \mathrm{THz}$, which dramatically increases the variation of the instantaneous power in the pulse edges leading to a much larger chirping. Fig. $3 b_{2}$ shows a relatively flat power level while frequency modulation in the order of $6 \mathrm{GHz}$ occurs; frequency discrimination will in this case generate a return-to-zero (RZ) NRZ recovered signal.

\section{Conclusions}

This paper studied the possibility of using EMLs for FSK modulation exploiting the chirp effect. The results from the simulation show the feasibility of achieving FSK and the obtained experimental data validates the hypothesis. The generated frequency shift suffices to employ frequency discriminators for signal recovery [6]. Future work focuses now on demonstrating multilevel FSK by exploiting the relatively linear response of the $\alpha$ factor.

\section{Acknowledgements}

The authors want to thank APEX Technologies for lending the complex optical spectrum analyzer.

\section{References}

1. P. J. Winzer, "Challenges and evolution of optical transport networks," in European Conference on Optical Communications, (Turin, 2010) paper We.8.D.1.

2. M. Chacinski, U. Westergren, B. Stoltz, L. Thylen, R. Schatz, and S. Hammerfeldt, "Monolithically integrated $100 \mathrm{GHz}$ dfb-tweam,” J. of Light. Tech., 27, 3410-3415, (2009).

3. P. Dong et al., "Low vpp, ultralow-energy, compact, highspeed silicon electro-optic modulator," Opt. Express , 17 22484-22490, (2009).

4. F. Koyama and K. Iga, "Frequency chirping in external modulators," IEEE J. of Light. Tech., 6 87-93 (1988).

5. Z. Tan et al., "Real-time wavelength and bandwidth-independent optical integrator based on modal dispersion," Opt. Express , 20, p.14109, (2012).

6. I. Tafur Monroy et al., "Techniques for labeling of optical signals in burst switched networks," in First International Workshop on Optical Burst Switching, (Dallas, 2003). 